\title{
Identification of Atovaquone as and Mebendazole as Repurposed Drugs with Antiviral Activity against SARS-CoV-2
}

Mahmoud S. Ahmed ${ }^{1 \#}$, Ayman B. Farag ${ }^{1 * \pi}$, Ping Wang ${ }^{1 *}$, Ian N. Boys ${ }^{2^{*}}$, Ivan Menendez-Montes ${ }^{1}$, Ngoc $^{2}$ Uyen Nhi Nguyen ${ }^{1}$ Jennifer L. Eitson ${ }^{2}$, Maikke B. Ohlson ${ }^{2}$, Wenchun Fan², Matthew B. McDougal ${ }^{2}$, Katrina Mar ${ }^{2}$, Francisco Ortiz ${ }^{6}$, Soo Young Kim${ }^{1}$, Ashley Solmonson ${ }^{8}$, Noelle S. Williams ${ }^{6}$, Andrew Lemoff $^{7}$, Ralph J. DeBerardinis ${ }^{8,9}$, John W. Schoggins ${ }^{2 \#}$ and Hesham A. Sadek ${ }^{1,3,4,5 \#}$

Departments of Internal Medicine ${ }^{1}$, Microbiology ${ }^{2}$, Molecular Biology ${ }^{3}$, Biophysics ${ }^{4}$, and Center for Regenerative Science and Medicine ${ }^{5}$, Department of Pharmacology ${ }^{6}$, Department Biochemistry ${ }^{7}$, Children's Medical Center Research Institute ${ }^{8}$, Howard Hughes Medical Institute ${ }^{9}$, University of Texas Southwestern Medical Center, Dallas, Texas 75390, USA.

"Author is currently at Department of Pharmaceutical Chemistry, Faculty of Pharmacy, Ahram Canadian University, 6th of October City, Giza, Egypt

${ }^{*}$ Authors contributed equally

\# Corresponding authors 


\title{
Correspondence:
}

\author{
Mahmoud S. Ahmed, PhD \\ Department of Internal Medicine/Division of Cardiology \\ University of Texas Southwestern Medical Center \\ 6000 Harry Hines Blvd \\ Dallas, Texas, 75390, USA \\ Email: Mahmoud.ahmed@utsouthwestern.edu
}

\section{John W. Schoggins, PhD}

Department of Microbiology

University of Texas Southwestern Medical Center

Dallas, Texas, 75390, USA

Email: john.schoggins@utsouthwestern.edu

\section{Hesham A. Sadek, MD, PhD}

Departments of Internal Medicine/Division of Cardiology,

Molecular Biology and Biophysics

University of Texas Southwestern Medical Center

6000 Harry Hines Boulevard

Dallas, Texas, 75390 , USA

Email: hesham.sadek@utsouthwestern.edu 


\begin{abstract}
Given the continuing heavy toll of the COVID-19 pandemic, therapeutic options for treatment are urgently needed. Here, we adopted a repositioning approach using in silico molecular modeling to screen FDA-approved drugs with established safety profiles for potential inhibitory effects against SARS-CoV-2. We used structure-based drug design to screen more than 2000 FDA approved drugs against SARS-CoV-2 main protease enzyme $\left(\mathrm{M}^{\text {pro }}\right)$ substrate-binding pocket. We additionally screened the top hits from both sites for potential covalent binding via nucleophilic thiol attack of Cys 145 . Highscoring candidates were then screened for antiviral activity against infectious SARS-CoV-2 in a cellbased viral replication assay, and counter screened for toxicity. Promising candidates included atovaquone, mebendazole, ouabain, dronedarone, and entacapone, although atovaquone and mebendazole were the only two candidates with IC50s that fall within their therapeutic plasma concentration. In addition, we performed $\mathrm{M}^{\text {pro }}$ assays on the top hits, which demonstrated inhibition of $\mathrm{M}^{\text {pro }}$ by dronedarone (IC50 $18 \mu \mathrm{M}$ ), mebendazole (IC50 $\left.19 \mu \mathrm{M}\right)$ and entacapone (IC50 $9 \mu \mathrm{M}$ ). Atovaquone showed only modest $\mathrm{M}^{\text {pro }}$ inhibition, and thus we explored other potential antiviral mechanisms. Although atovaquone is a known $\mathrm{DHODH}$ inhibitor, we did not observe inhibition of DHODH by atovaquone at concentrations relevant to the SARS-CoV-2 IC50. Interestingly, metabolomic profiling of atovaquone treated cells demonstrated marked dysregulation of metabolites in the purine metabolism pathway. In summary, a number of our top hits from the in-silico screen demonstrated $\mathrm{M}^{\text {pro }}$ inhibitory activity associated with antiviral effects. Atovaquone and mebendazole are the most promising candidates targeting SARS-CoV-2 from our screen, however atovaquone did not significantly inhibit $\mathrm{M}^{\text {pro }}$ at therapeutically meaningful concentrations but may inhibit SARS-CoV-2 viral replication by targeting host purine metabolism.
\end{abstract}




\section{Introduction}

SARS-CoV-2 was identified in late December 2019 as the etiological agent of a severe acute respiratory disease named COVID-19 [1-3]. The virus has since propagated worldwide, causing an unprecedented incidence of morbidity and mortality. Despite unprecedented efforts by the scientific community, which yielded a number of highly effective therapeutics, there are still no orally available antiviral agents, although a number are currently in late stage clinical trial [4]. As an alternative to de novo drug screening, drug-repurposing strategies provided a path towards identifying potential therapeutics that have established safety profiles and that can be used individually or in combination for targeting viral proteins or host factors required for viral replication [5-8]. To date, several strategies to identify and possibly repurpose drugs for SARS-CoV-2 have been reported [7, 9-11].

SARS-CoV-2 is a betacoronavirus and its genome encodes several structural proteins, including the glycosylated spike (S) protein that mediates viral attachment to the cells by binding to angiotensinconverting enzyme 2 (ACE2), a membrane bound carboxypeptidase [12-14]. Viral entry also appears to be mediated by priming of S protein facilitated by the host cell-produced serine protease TMPRSS2 $[12,15]$. In addition, the viral genome also encodes nonstructural proteins including an RNA-dependent RNA polymerase $(\mathrm{RdRp})$, main protease $\left(\mathrm{M}^{\text {pro }}\right)$, and papain-like protease (PLpro) [16-18]. Therefore, targeting ACE2, TMPRSS2, RdRp, $\mathrm{M}^{\text {pro }}$, and PLpro as individual targets, or in combination, may be a viable strategy for repurposed drugs.

A number of these viral proteins have been studied intensively from structural and medicinal chemistry perspectives owing to their potential role as therapeutic targets $[19,20]$ but perhaps $M^{\text {pro }}$ has been one of the most intensely studied SARS-CoV-2 proteins. $\mathrm{M}^{\text {pro }}$, a 33.8-kDa 3C-like protease, is responsible for proteolytic cleavage of the viral polyproteins $\mathrm{pp} 1 \mathrm{a}$ and $\mathrm{pp} 1 \mathrm{~b}$, which is required for viral replication and transcription. $\mathrm{M}^{\text {pro }}$ cleaves proteins at conserved sequences typically following a sequence that includes the amino acid glutamine, and has no homology to human proteases, which makes it an attractive drug target. One of the earliest structural publications on $\mathrm{M}^{\text {pro }}$ was an elegant study which solved the crystal structure of $\mathrm{M}^{\text {pro }}$ in complex with an inhibitory peptide N3 (PDB ID: 6LU7). Notably, the inhibitory peptide binds the substrate-binding pocket of SARS-CoV-2 $\mathrm{M}^{\text {pro }}$. Thus, we used this domain as the focus of an in-silico screen to identify FDA approved drugs with activity against $\mathrm{M}^{\text {pro. }}$. 


\section{Results}

The structural analysis for the peptide ligand N3 co-crystallized with SARS-CoV-2 M ${ }^{\text {pro }}$ substrate-binding pocket revealed a significant number of hydrophobic interactions and a hydrogen bond network comprising His163, His164, Glu166, Gln189, and Thr190 [21]. We decided to conduct an in silico molecular modeling study for $>2000$ FDA approved drugs focusing on two potential sites of the $\mathrm{M}^{\text {pro }}$ substrate-binding pocket based on the co-crystallized peptide N3.

\section{Central site molecular docking:}

The central site docking results showed the top 11 hits based on their $S$ score, binding affinity, interacting amino acids, and binding mode to fit the main protease pocket with respect to the reported clinical indication, as shown in Table 1. The rest of the top hits are listed in Table S1. Our three and two-dimensional analyses for the top hits are shown in Figures 1 and S1. Darunavir, a known antiviral protease inhibitor [22], showed the best binding affinity in terms of hydrophobic-hydrophobic and hydrogen bond interactions with His163, Glu166, and Thr190 at S score $-14.03040 \mathrm{Kcal} / \mathrm{mol}$. The top candidates also included antivirals such as Nelfinavir and Saquinavir with $\mathrm{S}$ scores ranging from $13.4200 \mathrm{Kcal} / \mathrm{mol}$ to $-12.0917 \mathrm{Kcal} / \mathrm{mol}$. The current repurposing study also includes other drugs approved for different clinical indications. For example, Moexipril, an ACE inhibitor [23], showed a proper binding mode via hydrophobic interactions and a hydrogen bond through a carboxylic acid moiety with Gln189 at S score $-13.2142 \mathrm{Kcal} / \mathrm{mol}$. Daunorubicin and Mitoxantrone are representatives for anthracene glycosidic chemotherapeutic agents[24, 25]. Daunorubicin showed potential binding affinity via hydrophobic interactions and hydrogen bonding with Asn142 and Glu166. Mitoxantrone showed hydrophobic interactions and a network of hydrogen bonds with His41, His164, Asp187, Thr190, and Gln192. The anthracene derivatives findings suggest that glycoside-based derivatives can target the substrate-binding pocket of SARS-CoV-2 M $\mathrm{M}^{\text {pro }}$. However, administration of chemotherapeutic agents can lead to significant adverse effects and is unlikely to be of any clinical utility in critically ill COVID-19 patients. Metamizole, a pyrazolone based derivative [26], showed a potential binding affinity via hydrogen bonds between a sulphonic acid moiety and His 163 and Ser144 in addition to pi-pi interaction with His41. Although metamizole might have clinical utility, it is also not an ideal candidate due to its association with agranulocytosis, which would be an unwelcomed side effect in COVID-19 patients. Bepotastine, an anti-histaminic [27, 28], exhibited proper binding affinity in the main substratebinding pocket via hydrophobic interactions and hydrogen bonding through a carboxylic acid moiety with GIn189. Atovaquone, an anti-malarial drug [29], showed a potential binding affinity with no hydrogen bonds with an S score $-8.4159 \mathrm{Kcal} / \mathrm{mol}$. Rosuvastatin, which belongs to the statins class of antihyperlipidemic drugs [30] displayed an excellent binding affinity in terms of free energy with an $S$ 
score of $-12.3096 \mathrm{Kcal} / \mathrm{mol}$. The Rosuvastatin skeleton filled the entire substrate-binding pocket via hydrophobic interactions and hydrogen bonding with Gly143 and Glu166.

Thus, structure-based drugs design for identifying the top hits targeting the central site of the substrate binding pocket elucidated the following preliminary pharmacophore features: (1) The entire pocket needs hydrophobic features or extended phenyl moieties to maintain a proper binding affinity such as in case of anthracene derivatives. (2) A network of hydrogen bonds (whether donors or acceptors) is a significant factor especially with amino acids Glu166, Gln189, His163, and His164. (3) The presence of terminal sulphonic acid and/or carboxylic acid moieties (Bepotastine, Moexipril, Metamizole, and Rosuvastatin) can act as bio-isosteric moieties to the phosphate groups that can be found in antiviral drugs.

\section{Terminal site molecular docking:}

The results of docking at the terminal site of the $\mathrm{M}^{\text {pro }}$ substrate-binding pocket revealed 8 top hits based on their S score, binding affinity, interacting amino acids, and binding mode to fit the terminal portion and with respect to the reported clinical indication, as shown in Table S2. Our three and two-dimensional analyses for the top hits targeting the terminal site are shown in Figures S2 and S3. Montelukast, an anti-asthmatic drug, showed the best binding affinity in terms of hydrophobic-hydrophobic and hydrogen bond interactions with Thr24, Ser46, and GIn189 at S score $-11.8226 \mathrm{Kcal} / \mathrm{mol}$. A recent report also showed the binding affinity of Montelukast to the same binding domain [31]. Lisinopril, an ACE inhibitor, showed proper binding mode via hydrophobic interactions and a hydrogen bond through a carboxylic acid and amine moieties with Thr26 and His164, respectively at S score $-11.5878 \mathrm{Kcal} / \mathrm{mol}$. Bumetanide, a loop diuretic showed a hydrogen bond network with Ser144, His163, Glu166, and GIn189; in addition to pi-pi interaction along with His41 at S score $-11.3008 \mathrm{Kcal} / \mathrm{mol}$. Fexofenadine, an anti-histaminic, protrudes towards the terminal groove of the protease binding pocket with hydrophobic-hydrophobic interactions and hydrogen bond with Thr26 at S score $-10.8085 \mathrm{Kcal} / \mathrm{mol}$. Pirbuterol, another anti-asthma with $\beta 2$ adrenergic activity, bound to the terminal site without further protrusion towards the center with hydrogen bonds Thr24, Thr25, and Ser46. Finally, Bosentan, an endothelin receptor antagonist used for pulmonary arterial hypertension, and quinidine showed hydrophobic interactions with no hydrogen bonds at S score $-10.0878 \mathrm{Kcal} / \mathrm{mol}$ and $-9.0607 \mathrm{Kcal} / \mathrm{mol}$. Although the dimensional size of the terminal site is limited compared to the central site for the $M^{\text {pro }}$ substrate-binding domain, the key amino acid residues for binding are Thr24, Thr25, Thr26, and Ser46.

\section{Covalent molecular docking:}

Finally, we performed an independent covalent docking study to identify FDA drugs that can target the catalytic amino acid Cys145 within the substrate-binding pocket, especially given that the co-crystallized 
inhibitor is peptide in nature ( $\alpha$ ketoamide) with covalent mode of binding [32]. We screened the top 200 drugs that resulted from the central and terminal molecular docking (top 100 for each) for targeted covalent docking through Cys145 via DOCKTITE's protocol by Molecular Operating Environment (MOE) [33]. This resulted in identifying 30 drugs that demonstrated possible nucleophilic attack by Cys 145 and undergo covalent docking to generate R and S stereoisomers. Only 9 candidates showed promising binding affinity with respect to $S$ score and covalent binding ability. Our three and twodimensional analysis for the top 9 covalent hits targeting Cys 145 is shown in Figures 2, S5, and S6.

\section{Antiviral activity assay:}

After completing in silico docking studies, we next used a cell-based assay to test the antiviral activity of selected compounds against SARS-CoV-2. An isolate of SARS-CoV-2 (USA-WA1/2020) was obtained and propagated in Vero E6 cells [34]. For initial drug screening, Vero E6 were infected with SARS-CoV-2 at 0.1-0.25 multiplicity of infection (MOI). After $1 \mathrm{hr}$, media containing drugs covering a 6$\log _{10}$ dilution series was added to the cells. Total RNA from virally infected cells was isolated $24 \mathrm{~h}$ postinfection and viral RNA replication was quantified by RT-qPCR using TaqMan probes. In parallel studies, drugs were screened for effects on cell viability and cellular metabolism by quantifying lactate dehydrogenase (LDH) release and cellular ATP levels (Cell Titer Glo), respectively.

From the 11 drugs identified by the central site docking method, we observed dose-dependent inhibition of SARS-CoV-2 with Atovaquone, Mitoxantrone, Daunorubicin, and Nelfinivir (Figure 3). LDH release assays showed that Daunorubicin and Nelfinivir were toxic to cells at high doses, whereas Atovaquone and Mitoxantrone did not elicit substantial LDH release. Of the 7 of the drugs identified by the terminal site docking method, Quinidine and Bosentan exhibited modest dose-dependent antiviral effects with minimal impact on LDH release and cellular ATP levels (Figure S7). Quinidine was reported in another drug screening study as a candidate antiviral for SARS-CoV-2 [35]. Of the top 7 of drugs that were predicted to exhibit covalent binding, we observed dose-dependent inhibition with Atovaquone, Ouabain, Dronedarone, Mebendazole, and Dronedarone, although Dronedarone appeared to be particularly toxic at IC50 concentrations (Figure 4a). Interestingly, Ouabain (and digoxin), which are cardiac glycoside, have recently been reported to inhibit SARS-CoV-2 infection [36, 37]. Together, 3 of the 7 covalent docking drugs (Atovaquone, Ouabain, and Mebendazole) exhibit antiviral effects in the absence of overt toxicity, suggesting a reasonable hit rate for the in-silico analysis (Figure 4b).

We next sought to validate several covalent docking candidates and determine cytotoxicity concentration at 50\% (CC50s) and inhibitory viral replication concentration at $50 \%$ (IC50s) over a 10ptdose response (Table 3). Viral infections were performed as described above in Vero E6 and human hepatoma Huh7.5 cells, followed by treating cells with 3-fold dilutions of Atovaquone, Ouabain, Dronedarone, and Mebendazole, starting at $100 \mu \mathrm{M}$, or in one set of experiments, $200 \mu \mathrm{M}$ Atovaquone. 


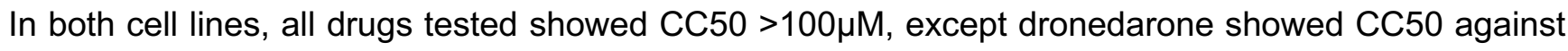
Vero E6 and Huh7.5 at 22.70 and $20.20 \mu \mathrm{M}$, respectively. In addition, the tested drugs recapitulated initial findings, though Mebendazole had less antiviral activity in Huh7.5 cells as compared to Vero E6 cells. We determined the following IC50s: Atovaquone (1.5 $\mu \mathrm{M}$ in Vero E6, 6.8 $\mu \mathrm{M}$ in Huh7.5); Ouabain (0.030 $\mu \mathrm{M}$ in Vero E6, $0.075 \mu \mathrm{M}$ in Huh7.5); Dronedarone (1.5 $\mu \mathrm{M}$ in Vero E6, $0.38 \mu \mathrm{M}$ in Huh7.5); Mebendazole (0.25-1.2 $\mu \mathrm{M}$ in Vero E6, but lacks strong inhibitory activity on Huh7.5 cells). In addition, we sought to visually demonstrate the antiviral effect of Atovaquone by indirect immunofluorescence, staining for virus-generated double-stranded RNA (dsRNA), a replication intermediate during coronavirus genome amplification, using a dsRNA-specific monoclonal antibody. We tested Atovaquone at $2.5 \mu \mathrm{M}$ and $7.5 \mu \mathrm{M}$ in Vero E6 cells and at $10 \mu \mathrm{M}$ in Huh7.5 cells transduced with lentivirus expressing the SARS-CoV-2 receptor ACE2. Drug-treated cells showed a striking reduction in dsRNA staining as compared to DMSO-treated control cells (Figure 4c). Data from DrugBank suggest that atovaquone is very highly protein bound (>99.9\%) [38]. To facilitate comparison of cell culture data with achievable therapeutic concentrations of atovaquone, we measured protein binding for this compound in tissue culture media and mouse and human plasma. Using rapid equilibrium dialysis, the unbound fraction (fu) of atovaquone was 0.0008 in tissue culture media containing 10\% FBS, 0.00003 in human plasma, and 0.0001 in murine plasma (Table S5). This suggests the free IC50 may be as low as 1.2 $\mathrm{nM}$ for Vero E6 cells. To validate this measurement, we repeated the antiviral assay in WHO Vero, a cell line adapted for serum-free growth. Under these conditions, the IC50 was $20 \mathrm{nM}$ (Figure 4d). As nonspecific binding to plasma proteins is a reversible event [39], it is not surprising that more drug may be locally available to bind a target that likely has a higher affinity, suggesting a possible reason for the discrepancy in values. However, for the purposes of comparing free drug levels in vitro and in vivo, we have used values based on the fu.

\section{$\underline{\mathrm{M}^{\text {pro }}}$ protein purification and activity assays:}

Next, we purified $\mathrm{M}^{\text {pro }}$ protein to determine the potential of the above-mentioned candidates to inhibit its

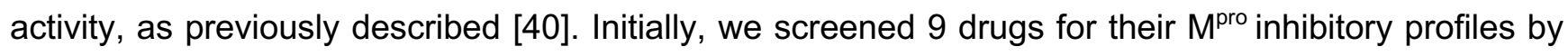
pre-incubating them at a single concentration $(50 \mu \mathrm{M})$ in the presence of $0.2 \mu \mathrm{M} \mathrm{M}^{\text {pro }}$ and $0.1 \mathrm{mM}$ DTT for 90 mins, followed by adding $M^{\text {pro }}$ fluorogenic substrate, using wavelengths of $360 \mathrm{~nm}$ and $460 \mathrm{~nm}$ for excitation and emission, respectively. Only entacapone and dronedarone showed $50 \%$ inhibition for the $\mathrm{M}^{\text {pro }}$ activity under these conditions. Next, we tested the effect of longer residence time on $\mathrm{M}^{\text {pro }}$ activity by incubating the candidate drugs for 12 hours with the purified protein, which demonstrated that entacapone, dronedarone, and mebendazole showed significant inhibition for the $\mathrm{M}^{\text {pro }}$ activity. However, atovaquone $(50 \mu \mathrm{M})$ demonstrated only a modest inhibitory effect of $\sim 35 \%$ on $\mathrm{M}^{\text {pro }}$ activity 
(Figure 5a). We subsequently screened entacapone, dronedarone, mebendazole at 10-dose levels against $\mathrm{M}^{\text {pro }}$ activity which demonstrated $\mathrm{IC}_{50}$ values of $9.04 \mu \mathrm{M}, 18.03 \mu \mathrm{M}$, and $19.94 \mu \mathrm{M}$, respectively (Figure 5b). Finally, we used tandem mass spectrometry analysis to identify potential covalent inhibitors targeting $\mathrm{M}^{\mathrm{pro}}$. We found that only entacapone demonstrated evidence of covalent modification of $\mathrm{M}^{\text {pro }}$, where $15-20 \%$ for $\mathrm{M}^{\text {pro }}$ was covalently modified (Figure $5 \mathrm{c}$ ). Collectively these results indicate that several of our top molecular docking hits exhibited $\mathrm{M}^{\text {pro }}$ inhibitory activity, but only entacapone showed evidence of covalent modification of $\mathrm{M}^{\text {pro }}$.

Atovaquone does not inhibit pyrimidine de-novo synthesis in Vero E6 cell lines at $1 \mu \mathrm{M}$ and $5 \mu \mathrm{M}$ :

Atovaquone is an attractive repurposing candidate given its safety and pharmacokinetic profile. However, since our assays failed to demonstrate a meaningful inhibitory effect of atovaquone against the purified $\mathrm{M}^{\text {pro }}$ protein at concentrations relevant to its antiviral IC50, we sought to determine other potential antiviral mechanisms of atovaquone. Atovaquone is known to inhibit dihydroorotate dehydrogenase (DHODH), an enzyme required for de novo pyrimidine synthesis, leading to specific depletion of intracellular nucleotides and eventually resulting in inhibition of viral replication of arthropodborne viruses (such as ZIKV and chikungunya virus)[41-43]. Therefore, we examined whether the antiviral effect of atovaquone is mediated by inhibition of $\mathrm{DHODH}$.

First, we performed metabolomic analysis of atovaquone-treated host (Vero E6) cells at $1 \mu \mathrm{M}$ and 5 $\mu \mathrm{M}$. The metabolomic profile demonstrated that atovaquone does not inhibit pyrimidine synthesis at concentrations relevant to the observed antiviral IC50s, as there was no significant change in the uridine 5'-mono-phosphate (UMP) levels versus orotate and dihydroorotate levels, compared to DMSO-treated cells. Consistent with published reports, we observed significant inhibition in pyrimidine synthesis at 10 $\mathrm{MM}$ ( 10-fold higher the IC50) (Figure 6). Second, we examined viral replication in the presence of $5 \mu \mathrm{M}$ and $100 \mu \mathrm{M}$ uridine treated with $1.5,5$, and $10 \mu \mathrm{M}$ atovaquone or $5 \mu \mathrm{M}$ vidofludimus (a selective DHODH inhibitor). In this scenario, uridine should reverse the observed inhibitory effect on viral replication if it is mediated by inhibition of pyrimidine synthesis. We found that atovaquone showed significant inhibition for viral replication regardless the uridine concentration, however vidofludimus inhibitory activity was reversed with addition of uridine. Collectively, these results demonstrate that the observed antiviral effect of atovaquone is likely not mediated by inhibition of DHODH.

Atovaquone inhibits purine de-novo synthesis in Vero E6 cell lines at $1 \mu \mathrm{M}$ and $5 \mu \mathrm{M}$ : 
The metabolomic prolife also demonstrated that atovaquone-treated cells showed significant depletion in the free guanosine, inosine, and adenosine at both 1 and $5 \mu \mathrm{M}$, suggesting that atovaquone may target host purine biosynthesis at concentrations equivalent to its antiviral IC50s.

\section{Atovaquone can distribute to lungs and epithelial lining fluid (ELF):}

Next, we performed a series of pharmacokinetic $(\mathrm{PK})$ studies to determine atovaquone levels in the plasma, lungs, and epithelial lining fluid (ELF) to determine whether therapeutic atovaquone levels can be achieved clinically. Mice were treated with $20 \mathrm{mg} / \mathrm{kg}$ PO daily for 7 days, which was followed by measuring total plasma atovaquone, free plasma atovaquone, and free ELF atovaquone concentrations. We chose this schedule because a preliminary analysis suggested a half-life for atovaquone in mice of approximately 18-38 hours, so we sought to achieve steady state for our analyses. With this dose and schedule, total plasma concentrations peaked at $100 \mu \mathrm{g} / \mathrm{mL}$ and free plasma levels peaked at approximately $16 \mathrm{ng} / \mathrm{ml}(44 \mathrm{nM})$. Free epithelial lining fluid (ELF) concentrations were similar to free plasma levels, peaking at $25 \mathrm{ng} / \mathrm{ml}(70 \mathrm{nM})$. We followed the standard practice of normalizing drug concentrations found in bronchial lavage fluid (BAL) by urea concentrations in plasma and BAL in order to determine ELF concentrations. Our urea measurements in BAL were 5-10 fold lower than those found in some literature reports [44]. As we used $\mathrm{CO}_{2}$ to euthanize our animals and there are some reports that $\mathrm{CO}_{2}$ may increase lung permeability [45], it is possible that permeability of urea was affected more significantly than that of the drug resulting in inaccurate assessment of atovaquone levels in ELF.

To translate these observations to human, we found that the maximum plasma concentration (Cmax) was higher compared to the reported single dose of atovaquone human oral suspension and approximately 2-5-fold higher compared to BID dosing in HIV infected volunteers [46]. Assuming linear $\mathrm{PK}$ in mice and similar biodistribution in human ELF, total human plasma concentrations of $15 \mu \mathrm{g} / \mathrm{mL}$ $(41 \mu \mathrm{M})$, may yield free plasma and ELF drug levels of at least $1.2 \mathrm{nM}$, close to the free IC50 for SARSCOV-2 determined based on free drug in tissue culture media. This plasma level is within observed steady state concentrations for atovaquone in HIV positive individuals $[47,48]$

\section{Mebendazole achieves IC50-relevant concentrations in ELF:}

We also performed PK studies to determine mebendazole levels in plasma, lungs, and ELF. Although we did not anticipate the same long half-life for mebendazole, we followed the same dosing schedule as atovaquone for consistency, treating mice with $10 \mathrm{mg} / \mathrm{kg}$ PO daily for 7 days. Subsequently, total plasma, free plasma, and free ELF levels of mebendazole were measured. We found that the maximum 
total plasma concentration was high within 90 mins after the last dose, with an average of $697.67 \mathrm{ng} / \mathrm{ml}$ (equivalent to $2.36 \mu \mathrm{M}$ ). Based on our determined free fraction of mebendazole in mouse plasma (Table S5), this gives rise to a maximum free drug concentration of approximately $90 \mathrm{ng} / \mathrm{ml}(305 \mathrm{nM})$. Interestingly, free drug levels in ELF were higher, nearing $550 \mathrm{ng} / \mathrm{ml}(1.8 \mu \mathrm{M})$ at peak, suggesting that it is within the observed free antiviral IC50 of Vero E6 cells. However, the same caveat noted above for calculation of free ELF concentrations of atovaquone applies here. Mice were euthanized with $\mathrm{CO}_{2}$, which may have influenced lung permeability differentially for mebendazole versus urea, which is used to calculate ELF concentrations from BAL measurements. Exposures noted here in mice are generally higher than those noted in the literature for humans receiving mebendazole. Peak plasma levels of patients receiving $10 \mathrm{mg} / \mathrm{kg}$ every 6 hours (total $40 \mathrm{mg} / \mathrm{kg} /$ day) reach only 0.3-1.69 $\mu \mathrm{M}$ [49]. Higher

doses have been shown to demonstrate improved exposure [50], so it is possible therapeutic concentrations may be achieved.

\section{Discussion}

In the current report, we demonstrate that screening FDA approved drugs against the SARS-CoV-2 virus $\mathrm{M}^{\text {pro }}$ substrate-binding pocket can identify candidate drugs with antiviral activity against SARSCoV-2 in cultured cells. This approach provides valuable insights to fast-track clinical trials for drugs with an established safety profile. In fact, atovaquone, one of the top candidates from the screen is currently being tested in a prospective randomized placebo controlled clinical trial. Nevertheless, there are several limitations of the current study that are worth discussing.

Only 3 of our top 30 hits, dronedarone, mebendazole, and entacapone, demonstrated measurable inhibitory activity against $\mathrm{M}^{\text {pro }}$ using purified protein in an enzymatic assay. In addition, only entacapone showed evidence of covalent modification of $\mathrm{M}^{\text {pro }}$ by mass spec, although it did not elicit a reproducible antiviral effect in cultured cells and thus an IC50 for this drug could not be calculated. Dronedarone is unlikely to have a real therapeutic value given that its antiviral activity tracks with its cellular toxicity, and its therapeutic plasma concentration (less than $300 \mathrm{nM}[51]$ ) is significantly lower than the measured IC50 of $1.5 \mu \mathrm{M}$. Mebendazole showed moderate inhibitory profile against $\mathrm{M}^{\text {pro }}$ and potent antiviral activity with IC50 of 0.25-1.2 $\mu \mathrm{M}$ in Vero E6 cells although it appears less effective in the human cell line Huh7.5 and thus further studies on other types of human cells are needed. It is unclear if therapeutically active concentrations against SARS-CoV-2 can be achieved in patients with a sufficiently high dose. Interestingly, ouabain had an IC50 against SARS-CoV-2 in the low nanomolar range, which is well within its therapeutic concentration [52]. However, ouabain, along with digoxin, both 
$\mathrm{Na}^{++} / \mathrm{K}^{+}$ATPase inhibitors, have a very narrow therapeutic index, which may limit their use in critically ill patients, especially those with impaired renal function or significant electrolyte abnormalities.

As outlined earlier, atovaquone and mebendazole are the leading candidates for repurposing based on their IC50, established safety profile, and PK properties. We performed additional PK studies to determine whether levels of these two drugs in airway epithelium reaches SARS-CoV-2 IC50 concentrations. We found that both drugs may achieve sufficient concentrations to be therapeutically meaningful, however it is worth noting here that our ELF urea concentrations were atypically low compared to previously published studies [44], potentially due to the use of $\mathrm{CO}_{2}$ for euthanasia, which could erroneously result in over estimation of ELF levels of both drugs. In addition, although serum levels of atovaquone can reach an excess of $40 \mu \mathrm{M}$, and has a high volume of distribution which results in its tissue accumulation [53] [54] [55], atovaquone is highly bound to plasma proteins. Therefore, it was important to determine both its IC50 against SARS-CoV-2 in serum free conditions, as well as to determine its free levels in vivo. Our results indicate that atovaquone inhibits viral replication in serum free conditions at exceedingly low concentrations (IC50 $20 \mathrm{nM}$ in serum free media and calculated free IC50 using fu of $1.2 \mathrm{nM}$ ). This free drug concentration was achievable in our PK studies in vivo in the airway epithelium, which supports a therapeutic role of atovaquone against SARS-CoV-2 that requires further clinical testing.

Our results also identified a potentially important new mechanism of action of atovaquone. Atovaquone does not appear to inhibit $\mathrm{M}^{\text {pro }}$ at concentrations relevant to the observed IC50 against SARS-CoV-2. It is important to also note here that although atovaquone was previously shown to exert an antiviral effect on other viruses by inhibiting pyrimidine metabolism through targeting $\mathrm{DHODH}$, this mechanism does not appear to be responsible for our observed antiviral effect on SARS-CoV-2. Our results however suggest that atovaquone markedly inhibits purine metabolism. Although there are no current antiviral drugs known to target purine metabolism, this has been proposed to be an important target for reducing the nucleotide pool necessary for viral replication, as well as possibly exerting anti-inflammatory effects[56].

In conclusion, our screen identified atovaquone and mebendazole as our top hits for targeting SARSCoV-2 based on their IC50, PK properties, and favorable side effect profile. Future studies are needed to validate their role as antiviral agents against SARS-CoV-2.

\section{Materials and Methods:}


FDA approved small molecules preparation: The U.S. FDA approved drug database was downloaded (drugbank.ca) and 3D structures were energy minimized using MMFF94 force field.

X-ray crystal structure preparation: Crystal structure of SARS-CoV-2 $\mathrm{M}^{\text {pro }}$ co-crystallized with an inhibitor has been resolved and accessed via PDB ID: 6LU7. A box was assigned for docking procedures within the hydrophobic binding domain of the peptide inhibitor.

Structure based in silico screening and scoring: The whole energy minimized library was enrolled in docking simulations using Molecular Operating Environment (MOE) along with PDB ID: 6LU7. The energy-minimized drugs underwent protonation states to add the missing hydrogens for proper ionization states. MOE docking module used to evaluate the favorable binding conformers based on London dG scoring method to estimate energy profile based on the binding affinity with respect to hydrophobic-hydrophobic interactions, hydrogen bonding, pi-pi interactions, and ionic interactions [57, 58]. Each drug gave 10 possible docked poses. The ideal pose for each drug was selected according to the similarity of its binding mode in the binding pocket to that of the co-crystallized peptide. Two dimensional diagrams were generated using MOE tools, while three dimensional figures were generated using PyMOL.

Covalent Docking using DOCKTITE: We used the covalent docking protocol to filter the top 200 FDA drug candidates. The filtering step involved combining automated warhead screening to reveal 31 candidates that can undergo nucleophilic attack by Cys 145 based on their chemical structure, nucleophilic side chain attachment with the right configuration (R or S), and pharmacophore-based docking. The chimeric poses underwent consensus scoring approach using MOE-internal empirical scoring functions [59]. The validation step will include pose predictions of 10 protein/ligand complexes with a cutoff mean RMSD of $2 \mathrm{~A}^{\circ}$.

Virus and cells: SARS-CoV-2 (strain USA-WA1/2020) was obtained from the World Reference Center for Emerging Viruses and Arboviruses, University of Texas Medical Branch. Virus was propagated by low MOI infection (MOI 0.01-0.001) in VeroE6 cells. When 70-90\% CPE was observed (48-72h postinfection), virus-containing supernatant was harvested, aliquot, and stored at $-80 \mathrm{C}$ until use. Viral titers were determined by TCID50 assay. VeroE6 cells (from C. Rice, The Rockefeller University) were grown in MEM (Gibco) supplemented with 10\% FBS (Gibco) and 1× non-essential amino acids (NEAA; Gibco). Huh7.5 and 293T cells (from C. Rice, The Rockefeller University) were grown in DMEM (Gibco) supplemented with 10\% FBS (Gibco) and 1× non-essential amino acids (NEAA; Gibco). Huh7.5 cells stably expressing ACE2 were maintained in DMEM supplemented with $4 \mu \mathrm{g} / \mathrm{mL}$ puromycin.

Lentiviral pseudoparticles: Lentiviral pseudoparticles were generated by transfection in 293T cells. Lentiviral pseudoparticles in the pSCRPSY backbone were generated as previously described[60]. A 
plasmid containing human ACE2 open reading frame was a kind gift of Neal Alto (UT Southwestern Medical Center).

SARS-CoV-2 infections: For screens, VeroE6 or Huh7.5 cells were seeded at 30,000 cells per well on 48 well plates approximately 16-20 hours before infection. Prior to infection, drugs were serially diluted in media to a concentration of $1.5 \mathrm{X}$ target concentration. For screens, 6-point 10-fold dilutions of drug were used, and for validation 10-point 3-fold dilutions were used. Cells were incubated with 0.1-0.25 MOI SARS-CoV-2 in a minimum volume of low-serum media for one hour to allow virus to bind and enter cells. After viral entry, media containing candidate compounds or vehicle control was added to cells to a final $1 \mathrm{X}$ concentration. All SARS-CoV-2 infections were performed in a Biosafety Level 3 (BSL3) facility according to institutional guidelines provided by the UT Southwestern Office of Business and Safety Continuity.

RNA isolations: Virus-infected cells were lysed in $300 \mu \mathrm{l}$ of TRI reagent 24 hours post-infection. Viral RNA was isolated using Direct-zol RNA Miniprep kits (ZymoResearch, \#R2053) according to manufacturer's protocol. Total RNA was eluted in $50 \mu$ l of DNase/RNase free water.

SARS-CoV-2 positive control: SARS-CoV-2 $\mathrm{N}$ gene was amplified from a synthesized $\mathrm{N}$ gene fragment (IDT) with primers that introduced a T7 promoter sequence on the 5' end (IDT) (Table S2). PCR product was purified using Qiagen PCR Purification Kit (Qiagen). In vitro transcription was performed using T7 RiboMAX Express Large Scale RNA Production System following manufacturers protocol (Promega). RNA was quantitated by nanodrop on DS-11 FX and by a fluorometer assay using the DeNovix RNA Assay (DeNovix). In-vitro transcribed RNA was used to generate a standard curve for qPCR from a 10fold dilution series starting at $5 \times 10^{10}$ copies of RNA.

RT-qPCR: A $25 \mu \mathrm{L}$ reaction contained $5 \mu \mathrm{L}$ RNA, $12.5 \mu \mathrm{L}$ of $2 x$ reaction buffer (containing $0.4 \mathrm{mM}$ of each dNTP and $6 \mathrm{mM} \mathrm{MgSO}_{4}$ ), $0.5 \mu$ of a $2.5 \mu \mathrm{M}$ ROX Reference Dye solution, $0.5 \mu \mathrm{L}$ SuperScript III

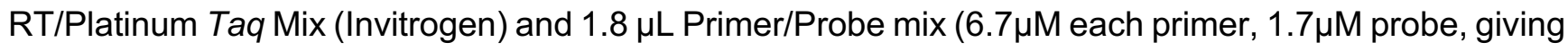
a final concentration of $500 \mathrm{nM}$ each primer, $125 \mathrm{nM}$ probe). SARS-CoV-2 primers and probe were designed as recommended by the Center for Disease Control (https://www.cdc.gov/coronavirus/2019ncov/lab/rt-pcr-panel-primer-probes.html). GAPDH primers and probe were designed as published [61] (Table S2). All oligonucleotides were synthesized by LGC Biosearch Technologies. RT was performed at $50^{\circ} \mathrm{C}$ for 5 minutes, followed by inactivation at $95^{\circ} \mathrm{C}$ for 2 minutes, and 40 cycles of PCR $\left(95^{\circ} \mathrm{C}\right.$ for 3 seconds, $60^{\circ} \mathrm{C}$ for 30 seconds) on an ABI 7500 Fast thermocycler (Applied Biosystems).

Cell viability and cell toxicity assays: VeroE6 cells seeded at 12,000 cells per well in 96 -well plates were incubated in the presence of each compound or DMSO as control diluted in MEM/10\% FBS for $24 \mathrm{~h}$. To quantify cell lysis, 50 microliters of cell supernatant was assayed for lactate dehydrogenase (LDH) 
release using the CytoTox 96 (Promega) assay according to manufacturer's instructions. To measure viable cells, the remaining media was aspirated from each well and replaced with 50 microliters of CellTiter-Glo (Promega) reagent diluted 1:1 with MEM/10\% FBS, and incubated $10 \mathrm{~min}$. Luminescence was measured for 30 microliters of each sample in a white-walled 96-well plate using a Berthold XS3 LB 960 luminometer.

Immunofluorescence: Cells were fixed with 3.7\% formaldehyde in water. Cells were washed with PBS, then permeabilized with $0.2 \%$ Triton-X 100 . Cells were blocked with $5 \%$ goat serum/PBS for at least 30 minutes. Primary antibody (J2, SciCons) was added in blocking solution and incubated for 1 hour. Cells were washed $3 x$ with PBS, after which secondary antibody (Goat-anti-mouse AlexaFluor 488, Invitrogen), was added in 5\% BSA/PBS and incubated for 30 minutes. Cells were washed 3x with PBS, and then mounted using Vectasheild Antifade Mounting Reagent with DAPI (VectorLabs). Imaging was performed on a Zeiss Observer Z.1. Images were processed in ImageJ.

Mpro protein cloning, expression, and purification: The gene for COVID-19 Mpro was cloned according to the published literature [40]. Briefly, the gene was constructed with $\mathrm{N}$ terminal GST tag followed by Mpro protease recognition site, Mpro protein, $3 \mathrm{C}$ protease recognition site and $6 \mathrm{xH}$ is tag. Target protein was expressed in cultures grown in autoinduction media at $18^{\circ} \mathrm{C}$ overnight [62]. The culture was harvested and sonicated in lysis buffer (50 mM Tris (pH8.0), $300 \mathrm{mM} \mathrm{NaCl}, 1 \mathrm{mM}$ DTT and supplemented with protease inhibitors). The lysate was centrifuged, the supernatant was loaded onto a Ni-NTA affinity column (Qiagen) and the beads were washed with wash buffer (20 mM Tris (pH8.0), $300 \mathrm{mM} \mathrm{NaCl}, 1 \mathrm{mM}$ DTT and 20mM Imidazole (pH 8.0)) and eluted with elution buffer (20 mM Tris (pH 8.0), $150 \mathrm{mM} \mathrm{NaCl}, 1 \mathrm{mM}$ DTT and $250 \mathrm{mM}$ Imidazole ( $\mathrm{pH}$ 8.0)). The eluate was digested by $3 \mathrm{C}$ protease at $4^{\circ} \mathrm{C}$ overnight and then further purified by ion exchange chromatography followed by gel filtration chromatography. The peak fractions were collected and concentrated to about $5 \mathrm{mg} / \mathrm{mL}$ with the gel filtration buffer (20 mM Tris (pH8.0), $150 \mathrm{mM} \mathrm{NaCl}, 1 \mathrm{mM}$ DTT and $1 \mathrm{mM}$ EDTA).

Mpro enzymatic activity and inhibition assays: Mpro enzymatic activity assays were executed, as previously described with minor modifications [63]. In brief, the SARS-CoV-2 M ${ }^{\text {pro }}$ activity was measured by incubation of $50 \mu \mathrm{M}$ of the selected compounds along with $0.2 \mu \mathrm{M}$ SARS-CoV-2 $\mathrm{M}^{\text {pro }}$ and $1 \mathrm{mM}$ DTT for 90 mins and 12h, followed by $20 \mu \mathrm{M}$ Mpro substrate, DABCYL-KTSAVLQSGFRKME-EDANS (BPS Bioscience, San Diego, CA, U.S.), using wavelengths of $360 \mathrm{~nm}$ and $460 \mathrm{~nm}$ for excitation and emission, respectively. Fluorescence intensity was monitored with microplate reader. All experiments were performed in triplicate. 
Next, we screened the Mpro activity for entacapone, dronedarone, and mebendazole at 10-dose levels $(0.04-50 \mu \mathrm{M})$. IC50s were elucidated using GraphPad Prism. All experiments were performed in duplicate.

Intact protein analysis in the presence of the compounds: Intact protein analysis in the presence of the compounds: Briefly, $12.5 \mu \mathrm{g}$ of SARS-Cov-2 Mpro was dissolved in $250 \mu$ of buffer $(10 \mathrm{mM}$ Tris. $\mathrm{HCl} \mathrm{pH}$ 7.5 buffer containing $0.1 \mathrm{mM}$ EDTA along with $2 \mu \mathrm{l}$ of $0.5 \mathrm{M}$ DTT to $1 \mathrm{ml}$ assay buffer), containing drug (ratio of 1:100), as previously described [7,64]. Liquid chromatography-mass spectrometry analyses were performed in positive-ion mode with a Sciex X500B quadrupole-time-of-flight mass spectrometer coupled with an Agilent 1290 Infinity II HPLC. Samples were injected onto a trap column packed with POROS 20 R1 reversed-phase beads and desalted for 4 minutes with buffer $A$ at $300 \mu \mathrm{L} / \mathrm{min}$, then eluted onto a POROS R1 reverse-phase column $(2.1 \times 30 \mathrm{~mm}, 20 \mu \mathrm{m}$ particle size, $4000 \AA$ pore size) with a gradient from $0-55 \%$ B in 18 minutes, 55-80\% B in 0.1 minutes, and held at $80 \%$ B for 4 minutes, as a flow rate of $300 \mu \mathrm{L} / \mathrm{min}$. Buffer A contained $0.1 \%$ formic in water and buffer $\mathrm{B}$ contained $0.1 \%$ formic acid in acetonitrile. The mass spectrometer was controlled by Sciex OS v.1.6.1 using the following settings: Ion source gas 130 psi, ion source gas 230 psi, curtain gas 35, CAD gas 7, temperature $300^{\circ} \mathrm{C}$, spray voltage $5500 \mathrm{~V}$, declustering potential $80 \mathrm{~V}$, collision energy $10 \mathrm{~V}$. Data was acquired from 400-2000 Da with a $0.5 \mathrm{~s}$ accumulation time and 4 time bins summed. The acquired mass spectra for the proteins of interest were deconvoluted using BioPharmaView v. 3.0.1 software (Sciex) to obtain the molecular weights. The peak threshold was set to $\geq 5 \%$, reconstruction processing was set to 10 iterations with a signal-to-noise threshold of $\geq 5$ and a resolution of 20000 .

Metabolomic analysis for atovaquone-treated Vero-E6 cells: For metabolomic studies, $10 \mathrm{~cm}$ culture dish of VeroE6 cells at $80 \%$ confluence were treated for $24 \mathrm{~h}$ with the indicated doses of atovaquone in regular culture medium. DMSO was used as vehicle control. After treatment, cells were washed with ice-cold PBS and scrapped out in $1 \mathrm{~mL}$ ice-cold $80 \%$ methanol. After three freeze-thaw cycles, cell debris was pelleted by centrifugation and metabolite-containing supernatant was evaporated using a SpeedVac concentrator (ThermoSavant, NY). Finally, metabolites were reconstituted in $0.03 \%$ formic acid. All metabolomics analysis were performed as the Metabolomics Core at CRI/UTSW. Targeted metabolite profiling of purine and pyrimidine pathways was performed, as previously described [65]. Untargeted metabolomics was performed by reverse-phase chromatography on a 1290 UHPLC liquid chromatography (LC) system interfaced to a high-resolution mass spectrometry (HRMS) 6550 iFunnel Q-TOF mass spectrometer (MS) (Agilent Technologies, CA). The MS was operated in both positive and negative (ESI+ and ESI-) modes. Analytes were separated on an Acquity UPLC $®$ HSS T3 column (1.8 $\mu \mathrm{m}, 2.1$ x $150 \mathrm{~mm}$, Waters, MA). The column was kept at room temperature. Mobile phase $A$ 
composition was $0.1 \%$ formic acid in water and mobile phase $B$ composition was $0.1 \%$ formic acid in $100 \%$ ACN. The LC gradient was 0 min: 1\% B; 5 min: 5\% B; 15 min: 99\% B; 23 min: 99\% B; 24 min:

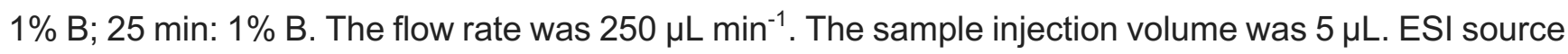
conditions were set as follows: dry gas temperature $225^{\circ} \mathrm{C}$ and flow $18 \mathrm{~L} \mathrm{~min}-1$, fragmentor voltage $175 \mathrm{~V}$, sheath gas temperature $350^{\circ} \mathrm{C}$ and flow $12 \mathrm{~L}$ min-1, nozzle voltage $500 \mathrm{~V}$, and capillary voltage $+3500 \mathrm{~V}$ in positive mode and $-3500 \mathrm{~V}$ in negative. The instrument was set to acquire over the full $\mathrm{m} / \mathrm{z}$ range of 40-1700 in both modes, with the MS acquisition rate of 1 spectrum s-1 in profile format. Raw data files (.d) were processed using Profinder B.08.00 SP3 software (Agilent Technologies, CA) with an in-house database containing retention time and accurate mass information on 600 standards from Mass Spectrometry Metabolite Library (IROA Technologies, MA) which was created under the same analysis conditions. The in-house database matching parameters were: mass tolerance $10 \mathrm{ppm}$; retention time tolerance $0.5 \mathrm{~min}$. Peak integration result was manually curated in Profinder for improved consistency and exported as a spreadsheet (.csv).

Atovaquone PK study: Female 6-weeks old CD1 mice (Charles River) were dosed PO qd x 7 at 20 $\mathrm{mg} / \mathrm{kg}$ atovaquone. Drug was clinical grade Mepron $(750 \mathrm{mg} / 5 \mathrm{~mL})$ diluted with $0.5 \%$ carboxymethylcellulose/0.5\% Kolliphor EL/1\% benzyl alcohol in $\mathrm{dH} 20$ to $2 \mathrm{mg} / \mathrm{ml}$. Dose volume was $10 \mathrm{~mL} / \mathrm{kg}$. Blood was collected via the submandibular route at various times post final dose and then animals were administered an inhalation overdose of $\mathrm{CO}_{2}$. The chest cavity was opened, and their trachea was exposed and supported by a curved forcep. A small incision was made to allow passage of an $18 \mathrm{~g}$ lavage catheter connected to a 3-way stockcock with $25 \mathrm{ml}$ syringes. The catheter was inserted and $\sim 0.5 \mathrm{ml}$ PBS injected 4 times with collection of bronchial lavage (BAL) fluid into the second syringe after each instillation. After the full volume was collected, the BAL in the output syringe was expelled into a fresh tube. The BAL was centrifuged at $9600 \times \mathrm{g}$ for $5 \mathrm{~min}$ to pellet cells and the supernatant and plasma were analyzed for compound by LC-MS/MS as described below. The urea content of both, also determined by LC-MS/MS, was used to normalize the BAL fluid content to determine the epithelial lining fluid (ELF) concentration. Plasma was diluted with commercial blank mouse plasma with EDTA. Time 0 was diluted at a 1:1 ratio. The 15- and 30-minute time points were diluted at a 1:10 dilution. The remaining time points were diluted at a 1:50 dilution. Standards and controls were prepared using standard stock solutions of atovaquone made in DMSO spiked into commercial blank mouse plasma collected with K2EDTA anticoagulant. BAL samples were run undiluted. Standards and controls were prepared using standard stocks in blank BAL. To all samples, $10 \mu \mathrm{L}$ of internal standard (atovaquone-d4) diluted in $30 \mathrm{mM} \mathrm{NH}_{4}$ Acetate was added and samples vortexed. $400 \mu \mathrm{L}$ of ethyl acetate was added to each sample. Tubes were vortexed for $30 \mathrm{sec}$, incubated at room temperature (RT) for 5 minutes and spun for 5 minutes at $16,100 \times \mathrm{g}$. Supernatant was transferred to a second tube. To the first tube, $400 \mu \mathrm{L}$ of ethyl acetate was added. Tubes were 
vortexed for $15 \mathrm{sec}$, incubated at RT for 5 minutes and spun for 5 minutes at 16,100 x g. Supernatant was removed and added to the tube containing supernatant previously collected. Samples were dried down under vacuum and then resuspended in $100 \mu \mathrm{L}$ of $20: 80 \mathrm{dH}_{2} \mathrm{O}$ : acetonitrile, $5 \mathrm{mM} \mathrm{NH}_{4}$ Acetate. Samples were vortexed for 15 seconds, sonicated for 3 minutes and spun for 5 minutes at 16,100 x g. Supernatant was transferred to an HPLC vial and analyzed on a Sciex 4000QTRAP coupled to a Shimadzu Prominence LC using a fit-for-purpose method. Atovaquone was detected in negative multiple reaction monitoring (MRM) mode using the following transitions: 365.096 to 337.0 (quantitation ion), 365.096 to 170.8 (qualifier ion). Atovaquone-d4 was detected using the 369.1 to 341.0 transition. An isocratic flow of $0.2 \mathrm{~mL} / \mathrm{min} 2 \mathrm{mM} \mathrm{NH}_{4}$ acetate with $0.8 \mathrm{~mL} / \mathrm{min}$ of acetonitrile on an Agilent C18 XDB column (5-micron, $50 \times 4.6 \mathrm{~mm}$ ) was used for chromatography. Atovaquone and Atovaquone-d4 showed a retention time of 1.73 min using this method. Concentrations were determined by comparison to a 9-point standard curve. Greater than $75 \%$ of standards and $100 \%$ of quality control (QC) samples were within $15 \%$ of nominal upon back-calculation. The limit of detection (LOD) was defined to be three-fold above the signal observed in blank plasma and the limit of quantitation (LOQ) was defined as the lowest point on the standard curve above the limit of detection and within $20 \%$ of nominal. The LOQ was $1 \mathrm{ng} / \mathrm{mL}$ for both matrices. Recovery of analyte at low, medium, and high concentrations was $>90 \%$ for plasma and BAL.

Epithelial Lining Fluid (ELF) concentrations were determined using urea normalization with the following calculation after correction for free atovaquone levels in BAL

$$
\mathrm{V}_{\mathrm{ELF}}=\mathrm{V}_{\mathrm{BAL}} \times \text { Urea }_{\mathrm{BAL}} / \text { Ureaplasma, where } \mathrm{V}_{\mathrm{BAL}} \text { is the volume of aspired BAL fluid. }
$$

The concentration of atovaquone in ELF (Atovaquone $\mathrm{ELF}_{\mathrm{L}}$ ) was determined from the equation

$$
\text { Atovaquone }_{\mathrm{ELF}}=\text { Atovaquone }_{\mathrm{BAL}} \times \mathrm{V}_{\mathrm{BAL}} / \mathrm{V}_{\mathrm{ELF}}
$$

Urea levels were determined by LC-MS/MS using a Sciex 6500+ QTRAP coupled to a Shimadzu NexeraX2 LC. To $100 \mu \mathrm{L}$ sample, $30 \mu \mathrm{l}$ of an internal standard solution containing $10 \mu \mathrm{g} / \mathrm{mL}{ }^{13} \mathrm{C},{ }^{15} \mathrm{~N}$ urea and ${ }^{15} \mathrm{~N}$ urea was added. $150 \mu \mathrm{L}$ of $2 \mathrm{M} \mathrm{NaCO}_{3}$ was added and the solution vortexed for $2 \mathrm{~min}$. $900 \mu \mathrm{L}$ acetonitrile was added and the solution pipeted 20 times up and down to mix. The solution was centrifuged for $10 \mathrm{~min}$ at $16,100 \times \mathrm{g} 4^{\circ} \mathrm{C}$. $600 \mu \mathrm{L}$ of the upper organic layer was transferred to a new tube and dried down under vacuum with mild heat. The solution was resuspended in 100 $\mu \mathrm{L}$ 50:50 acetonitrile: $\mathrm{dH}_{2} \mathrm{O}$ and evaluated by LC-MS/MS. Urea was detected in positive multiple reaction monitoring (MRM) mode using the following transition: 61.0 to 44.0 . ${ }^{15} \mathrm{~N}-$ Urea was detected as the 63.0 to 45.0 transition and ${ }^{13} \mathrm{C}^{15} \mathrm{~N}$-Urea was detected as 64.0 to 46 . A gradient flow of $20 \mathrm{mM} \mathrm{NH}_{3}$ formate (Buffer A) and Acetonitrile (Buffer B) was used with a Phenomenex Luna 3-micron HILIC column (100 x $4.6 \mathrm{~mm}, 200 \AA)$ : $0-1.5 \mathrm{~min}$ gradient from $97 \% \mathrm{~B}$ to $60 \% \mathrm{~B}, 1.5$ to $2.060 \% \mathrm{~B}, 2.0$ to 4.2 
min gradient to $97 \%$ B,4.2 to 5.0 min $97 \%$ B. Concentrations were determined by comparison to an 8 or 10-point standard curve prepared by spiking diluted mouse plasma or BAL with urea standards made in DMSO. Greater than $75 \%$ of standards and QCs were within 15\% of nominal upon backcalculation. The LOQ for plasma was $10 \mu \mathrm{g} / \mathrm{mL}$ and for BAL it was $0.1 \mu \mathrm{g} / \mathrm{mL}$. Free drug was determined by multiplying the total drug concentration by the free fraction for atovaquone in each matrix as determined by rapid equilibrium dialysis (see below). Noncompartmental PK parameters were determined with sparse sampling using WinNonlin (Pharsight).

Mebendazole PK study: Female 6-weeks old CD1 mice (Charles River) were dosed PO qd x 7 at 20 $\mathrm{mg} / \mathrm{kg}$ with mebendazole (Sigma). Drug was resuspended in DMSO such that the final concentration of DMSO was $10 \%$ and diluted with $0.5 \%$ carboxymethylcellulose/0.5\% Kolliphor EL/1\% benzyl alcohol in $\mathrm{dH} 20$ to $2 \mathrm{mg} / \mathrm{mL}$. Dose volume was $10 \mathrm{~mL} / \mathrm{kg}$. Collection of blood and BAL were as described for atovaquone. Plasma was diluted with commercial blank mouse plasma with EDTA. Time 0 was diluted at a 1:1 ratio. The 15-minute timepoint was diluted at a 1:5 dilution. 30-, 90-, and 360- timepoints were diluted at 1:10. 180- timepoint was diluted at 1:20. 720-timepoint was diluted at 1:2. The 1440timepoint was run undiluted. Each sample had a final volume of $50 \mu \mathrm{L}$. Standards and controls were prepared using standard stocks and blank commercial plasma for a total volume of $50 \mu \mathrm{L} .100 \mu \mathrm{L}$ of Acetonitrile crash (50 ng/mL mebendazole-d3, 0.1\% formic acid final) was added to each sample. Samples were vortexed for 15 seconds, incubated at room temperature for 10 minutes and spun for 5 minutes at $16,100 x$ twice. Supernatant was analyzed by LC-MS/MS using a Sciex 4000QTRAP coupled to a Shimadzu Prominence LC. Mebendazole was detected in positive multiple reaction monitoring (MRM) mode using the following transitions: 296.145 to 264.014 (quantifier ion), 296.145 to 105.053 (qualifier ion). The IS mebendazole-d3 was detected as the 299.19 to 105.1 transition. An isocratic flow of $0.2 \mathrm{ml} / \mathrm{min} 0.1 \%$ formic acid in $\mathrm{dH}_{2} \mathrm{O}$ (Buffer $\mathrm{A}$ ) and $0.8 \mathrm{ml} / \mathrm{min} 0.1 \%$ formic acid in Acetonitrile (Buffer B) was used with an Agilent C18 XDB column (5-micron, 50 x $4.6 \mathrm{~mm}$ ). Mebendazole and mebendazole-d3 showed a retention time of 2.42 min with this method. Concentrations were determined by comparison to an 8 to 10-point standard curve prepared by spiking diluted mouse plasma or BAL with mebendazole standards made in DMSO. Greater than $75 \%$ of standards and QCs were within $15 \%$ of nominal upon back calculation. The LOQ for plasma and BAL was $1 \mathrm{ng} / \mathrm{mL}$. Analysis of both matrices was as described for atovaquone.

Protein Binding: Binding of compounds in matrix was determined by rapid equilibrium dialysis. Briefly compounds were spiked at concentrations indicated into diluted mouse or human plasma (20x), straight BAL or tissue culture media containing $10 \%$ FBS. Samples $(200 \mu \mathrm{L})$ in duplicate or triplicate were placed 
in the red side chamber of a Pierce RED device and $350 \mu \mathrm{L}$ of PBS added to the white chamber. Plates were sealed and rocked gently at $37^{\circ} \mathrm{C}$ for $4-6 \mathrm{hrs}$. Mebendazole binding was done in a $5 \% \mathrm{CO} 2$ atmosphere. At the end of the incubation, aliquots were removed from the PBS and then matrix chamber and mixed with an equal volume of matrix or PBS respectively. Samples were then processed and analyzed by LC-MS/MS as described above for PK samples. Stability of each compound in all matrices was assessed at the same time by incubating each compound in matrix for the same period and was always $>90 \%$. All concentrations are approximated by peak area ratio of analytes/IS in the LCMS. Binding was determined according to the following calculation

$$
\% P P B=\frac{C_{R}-C_{W}}{C_{R}} \times 100 \%
$$

Where $C_{R}$ is total drug concentration in plasma in red chamber, $C_{W}$ is free drug concentration in white chamber. Dilution of matrix was accounted for as follows: Undiluted fu $=\frac{1 / D}{\left(\left(\frac{1}{f u_{2}}\right)-1\right)+1 / D}$

Where $D$ is the dilution factor and $\mathrm{fu}_{2}$ is the fraction unbound in the diluted matrix [66].

\section{Figure Legends:}

Figure 1. Docked positions to the central site of the substrate binding-pocket of SARS-CoV-2 $\mathrm{M}^{\text {pro: }} \mathrm{A}$ ) 3D presentation of the pocket. B) Overlayed docked positions of all 11 top hits in addition the previously co-crystallized inhibitory peptide N3. C) Individual docking positions.

Figure 2. Docked positions for the covalently bound candidates targeting Cys 145 of SARS-CoV-2 Mpro

Figure 3. Antiviral activity of drugs identified by central site docking for Vero E6 cells infected with SARS-CoV-2. SARS-CoV-2 replication was quantified by TaqMan RT-PCR. Drug-induced effects on cells was monitored by quantifying LDH release and ATP levels. Data represent the averages of two biological replicates. Error bars, SEM.

Figure 4. (A) Antiviral activity of drugs predicted to covalently bind to $\mathrm{M}^{\text {pro }}$ active site for Vero E6 infected with SARS-CoV-2. SARS-CoV-2 replication was quantified by TaqMan RT-PCR. Drug-induced effects on cells was monitored by quantifying LDH release and ATP levels. Data represent the averages of two biological replicates. Error bars, SEM. (B) Validation of antiviral activity of atovaquone, mebendazole, dronedarone, and ouabain by 10pt curve analysis in Vero E6 and Huh7.5 cells infected with SARSCoV-2. SARS-CoV-2 replication was quantified by TaqMan RT-PCR. LDH data are duplicated from previous figures. DMSO is shown as a control for effects of vehicle on infection in Huh7.5 cells. Data represent the averages of three biological replicates for Atovaquone "second viral prep" and two 
replicates for all others. Error bars, SEM. (C) Cells were stained with anti-dsRNA antibody $24 \mathrm{~h}$ postinfection. N=1. B. Huh7.5 cells ectopically expressing ACE2 were treated with one dose of Atovaquone $1 \mathrm{~h}$ after infection with SARS-CoV-2. Cells were stained with anti-dsRNA antibody $10 \mathrm{~h}$ post-infection. Data are representative of images obtained from 1 (Vero E6) or 2 (Huh7.5) independent experiments. (D) Antiviral activity of atovaquone in Vero E6 cells infected with SARS-CoV-2 under serum-free conditions.

Figure 5. (A) Effect of residence time of pre-incubation of $0.2 \mu \mathrm{M}$ Mpro in the presence of $1 \mathrm{mM}$ DTT and the selected drugs at concentration of $50 \mu \mathrm{M}$ (90 mins and 12h) on Mpro activity, DMSO concentration did not exceed $10 \%$. This was followed by adding fluorogenic substrate to measure fluorescence intensity using microplate reader at wavelengths of $360 \mathrm{~nm}$ and $460 \mathrm{~nm}$ for excitation and emission, respectively. Data represent average of triplicates. Error bars,SEM. (B) Dose-response curve for entacapone, dronedarone, and mebendazole to elucidate IC50 using GraphPad Prism. Data represent average of duplicates. Error bars, SEM. (C) Intact mass analyses for Mpro and Mpro incubated with entacapone at a ratio of (1:100), followed by tandem mass spectrometry.

Figure 6. Atovaquone does not target pyrimidine synthesis pathway Vero E6 cells at 1 and $5 \mu \mathrm{M}$. (A) Metabolomic analyses for of Vero E6 cells treated with DMSO or Atovaquone, at, showing no change in the uridine monophosphate (UMP) levels at 1 and $5 \mu \mathrm{M}$, and significant depletion in UMP levels at 10 $\mu \mathrm{M}$. (B) Molecular pathway of de novo pyrimidine synthesis. (C) Levels of UMP with respect to orotate and dihydroorotate levels in Vero E6 cells treated with 1,5, and $10 \mu \mathrm{M}$ atovaquone, showing only depletion in the UMP levels at $10 \mu \mathrm{M}$ ATO. (D)SARS-CoV-2 replication in the presence of $5 \mu \mathrm{M}$ and 100 $\mu \mathrm{M}$ uridine treated with $1.5,5$, and $10 \mu \mathrm{M}$ atovaquone or $5 \mu \mathrm{M}$ vidofludimus (potent DHODH inhibitor). Atovaquone showed significant inhibition for viral replication regardless the uridine concentration, however vidofludimus activity changed based on the uridine addition. Data represent average of biological triplicates. Error bars, SEM.

Figure 7. Atovaquone targets purine synthesis pathway for the Vero E6 cells. (A) Metabolomic analyses for DMSO and Atovaquone treated Vero E6 cells at 1, 5, and $10 \mu \mathrm{M}$, showing downregulation of adenosine, guanosine, and inosine levels. (B) Molecular pathway of de novo purine synthesis. (C) Levels of free guanosine, inosine, and adenosine with respect to GMP, IMP, and AMP at Vero-E6 cells treated with 1 and $5 \mu \mathrm{M}$ ATO. Error bars, SEM.

Figure 8. (A) Pharmacokinetics profiling for (A) Atovaquone and (B) Mebendazole.

Table 1. List of top drugs docked to the central domain of SARS-CoV-2 Mpro substrate-binding pocket based on S score. 
Table 2. List of top drugs docked covalently to Cys 145 of SARS-CoV-2 virus Mro substrate-binding pocket showing the configuration of nucleophilic attack and S score.

Table 3. Cytotoxicity concentration at $50 \%\left(\mathrm{CC}_{50}\right)$ and inhibitory concentration at $50 \%\left(\mathrm{IC}_{50}\right)$ profile for selected drugs against Vero E6 and Huh7.5 cells infected with SARS-CoV-2.

\section{Supporting Information:}

Figure S1. Workflow: A) Crystal structure of SARS-CoV-2 $\mathrm{M}^{\text {pro }}$ highlighting the substrate binding-pocket which was used for docking. B) Schematic diagram for in silico drug repositioning.

Figure S2. Two-dimensional presentation of docking poses for top 11 candidates targeting central site of protease domain. Blue arrows are backbone hydrogen bonds and green arrows are the side chain hydrogen bonds.

Figure S3. Docked positions to the terminal site for substrate binding-pocket of SARS-CoV-2 Mpro: A) 3D presentation of the pocket. B) Overlayed docked positions of all 8 top hits in addition to the previously co-crystallized inhibitory peptide N3. C) Individual docking positions.

Figure S4. Two-dimensional presentation of docking poses for top 8 candidates targeting terminal site of protease domain. Blue arrows are backbone hydrogen bonds and green arrows are the side chain hydrogen bonds.

Figure S5. Two-dimensional presentation of covalent docking poses for top 9 candidates targeting Cys 145 of the protease domain. Blue arrows are backbone hydrogen bonds and green arrows are the side chain hydrogen bonds.

Figure S6. Antiviral activity of drugs identified by terminal site docking. SARS-CoV-2 replication was quantified by TaqMan RT-PCR. Drug-induced effects on cells was monitored by quantifying LDH release. Data represent the averages of two biological replicates. Error bars, SEM. 
Table S1. List of the remaining top drugs bound to the central site of protease domain based on $S$ score.

Table S2. List of top drugs docked to the terminal domain of COVID-19 virus Mpro substrate-binding pocket based on S score.

Table S3. Oligos used to generate $\mathrm{N}$ gene RNA by T7 transcription

\begin{tabular}{|c|c|}
\hline Oligonucleotide & Sequence \\
\hline T7-SARS-CoV-2_N & TAA TAC GAC TCA CTA TAG GGA TGT CTG ATA ATG GAC CCC AAA ATC AGC \\
\hline SARS-CoV-2-Notl & CTA ATT GCG GCC GCT TAG GCC TGA GTT GAG TCA GCA C \\
\hline
\end{tabular}

Table S4. Oligos used for RT-qPCR

\begin{tabular}{|c|c|r|}
\hline Assay & Oligonucleotide & Sequence $^{\text {a }}$ \\
\hline \multirow{3}{*}{$\begin{array}{c}\text { SARS- } \\
\text { CoV-2 }\end{array}$} & SARS-CoV-2_N1-F & GAC CCC AAA ATC AGC GAA AT \\
\cline { 2 - 3 } & SARS-CoV-2_N1-R & TCT GGT TAC TGC CAG TTG AAT CTG \\
\cline { 2 - 3 } & SARS-CoV-2_N1-P & FAM-ACC CCG CAT TAC GTT TGG TGG ACC-BHQ1 \\
\cline { 2 - 3 } GAPDH & GAPDH_F & GAAGGTGAAGGTCGGAGTCAAC \\
\cline { 2 - 3 } & GAPDH_R & CAGAGTTAAAAGCAGCCCTGGT \\
\cline { 2 - 3 } & GOE-P & JOE-TTGGTCGTATTGGGCGCCT-BHQ1 \\
\hline
\end{tabular}

a FAM: 6-carboxyfluorescein; JOE: 4',5'-dichloro-2',7'-dimethoxy-6-carboxyfluorescein, BHQ-1: Black Hole Quencher 1

Table S5. Determination of Free Fraction for Atovaquone and Mebendazole in Various Matrices

\section{References:}

1. Malik, Y.S., et al., Emerging novel coronavirus (2019-nCoV)-current scenario, evolutionary perspective based on genome analysis and recent developments. Vet Q, 2020. 40(1): p. 6876.

2. Wu, F., et al., A new coronavirus associated with human respiratory disease in China. Nature, 2020. 579(7798): p. 265-269.

3. Zhou, P., et al., A pneumonia outbreak associated with a new coronavirus of probable bat origin. Nature, 2020. 579(7798): p. 270-273. 
4. Sanders, J.M., et al., Pharmacologic Treatments for Coronavirus Disease 2019 (COVID-19): A Review. JAMA, 2020. 323(18): p. 1824-1836.

5. Gordon, D.E., et al., A SARS-CoV-2 protein interaction map reveals targets for drug repurposing. Nature, 2020. 583(7816): p. 459-468.

6. Gordon, D.E., et al., Comparative host-coronavirus protein interaction networks reveal panviral disease mechanisms. Science, 2020. 370(6521): p. eabe9403.

7. Jin, Z., et al., Structure of Mpro from SARS-CoV-2 and discovery of its inhibitors. Nature, 2020. 582(7811): p. 289-293.

8. Rut, W., et al., SARS-CoV-2 Mpro inhibitors and activity-based probes for patient-sample imaging. Nature Chemical Biology, 2021. 17(2): p. 222-228.

9. Drayman, N., et al., Masitinib is a broad coronavirus $3 C L$ inhibitor that blocks replication of SARS-CoV-2. Science, 2021: p. eabg5827.

10. Sacco, M.D., et al., Structure and inhibition of the SARS-CoV-2 main protease reveal strategy for developing dual inhibitors against $M<$ sup $>$ pro $</$ sup $>$ and cathepsin $L$. Science Advances, 2020. 6(50): p. eabe0751.

11. Qiao, J., et al., SARS-CoV-2 $M<$ sup $>$ pro $</$ sup $>$ inhibitors with antiviral activity in a transgenic mouse model. Science, 2021. 371(6536): p. 1374-1378.

12. Hoffmann, M., et al., SARS-CoV-2 Cell Entry Depends on ACE2 and TMPRSS2 and Is Blocked by a Clinically Proven Protease Inhibitor. Cell, 2020. 181(2): p. 271-280 e8.

13. Wrapp, D., et al., Cryo-EM structure of the 2019-nCoV spike in the prefusion conformation. Science, 2020. 367(6483): p. 1260-1263.

14. Yan, R., et al., Structural basis for the recognition of SARS-CoV-2 by full-length human ACE2. Science, 2020. 367(6485): p. 1444-1448.

15. Hoffmann, M., H. Kleine-Weber, and S. Pohlmann, A Multibasic Cleavage Site in the Spike Protein of SARS-CoV-2 Is Essential for Infection of Human Lung Cells. Mol Cell, 2020.

16. Hoffmann, M., et al., SARS-CoV-2 Cell Entry Depends on ACE2 and TMPRSS2 and Is Blocked by a Clinically Proven Protease Inhibitor. Cell, 2020.

17. Gorbalenya, A.E., et al., Nidovirales: evolving the largest RNA virus genome. Virus Res, 2006. 117(1): p. 17-37.

18. Baez-Santos, Y.M., S.E. St John, and A.D. Mesecar, The SARS-coronavirus papain-like protease: structure, function and inhibition by designed antiviral compounds. Antiviral Res, 2015. 115: p. 21-38.

19. Gil, C., et al., COVID-19: Drug Targets and Potential Treatments. Journal of Medicinal Chemistry, 2020. 63(21): p. 12359-12386.

20. Liu, C., et al., Research and Development on Therapeutic Agents and Vaccines for COVID-19 and Related Human Coronavirus Diseases. ACS Central Science, 2020. 6(3): p. 315-331.

21. Wang, F., et al., Structure of Main Protease from Human Coronavirus NL63: Insights for Wide Spectrum Anti-Coronavirus Drug Design. Sci Rep, 2016. 6: p. 22677.

22. Li, D., et al., Investigation on the mechanism for the binding and drug resistance of wild type and mutations of G86 residue in HIV-1 protease complexed with Darunavir by molecular dynamic simulation and free energy calculation. J Mol Model, 2014. 20(2): p. 2122.

23. Kalasz, H., et al., Metabolism of moexipril to moexiprilat: determination of in vitro metabolism using HPLC-ES-MS. Med Chem, 2007. 3(1): p. 101-6.

24. Pang, B., et al., Drug-induced histone eviction from open chromatin contributes to the chemotherapeutic effects of doxorubicin. Nat Commun, 2013. 4: p. 1908.

25. Wu, C.C., et al., On the structural basis and design guidelines for type II topoisomerasetargeting anticancer drugs. Nucleic Acids Res, 2013. 41(22): p. 10630-40.

26. Garcia-Martin, E., et al., Genetic determinants of metamizole metabolism modify the risk of developing anaphylaxis. Pharmacogenet Genomics, 2015. 25(9): p. 462-4. 
27. Takahashi, D., et al., Backbone and side-chain (1)H, (1)(5)N, and (1)(3)C resonance assignments of Norwalk virus protease. Biomol NMR Assign, 2012. 6(1): p. 19-21.

28. Takahashi, H., A. Ishida-Yamamoto, and H. lizuka, Effects of bepotastine, cetirizine, fexofenadine, and olopatadine on histamine-induced wheal-and flare-response, sedation, and psychomotor performance. Clin Exp Dermatol, 2004. 29(5): p. 526-32.

29. Hughes, W., et al., Comparison of atovaquone (566C80) with trimethoprim-sulfamethoxazole to treat Pneumocystis carinii pneumonia in patients with AIDS. N Engl J Med, 1993. 328(21): p. 1521-7.

30. Jones, P.H., et al., Comparison of the efficacy and safety of rosuvastatin versus atorvastatin, simvastatin, and pravastatin across doses (STELLAR* Trial). Am J Cardiol, 2003. 92(2): p. 15260.

31. Wu, C., et al., Analysis of therapeutic targets for SARS-CoV-2 and discovery of potential drugs by computational methods. Acta Pharmaceutica Sinica B, 2020.

32. Zhang, L., et al., Crystal structure of SARS-CoV-2 main protease provides a basis for design of improved a-ketoamide inhibitors. Science, 2020: p. eabb3405.

33. Scholz, C., et al., DOCKTITE-a highly versatile step-by-step workflow for covalent docking and virtual screening in the molecular operating environment. J Chem Inf Model, 2015. 55(2): p. 398-406.

34. Harcourt, J., et al., Severe Acute Respiratory Syndrome Coronavirus 2 from Patient with 2019 Novel Coronavirus Disease, United States. Emerg Infect Dis, 2020. 26(6).

35. Touret, F., et al., <em $>$ In vitro</em $>$ screening of a FDA approved chemical library reveals potential inhibitors of SARS-CoV-2 replication. bioRxiv, 2020: p. 2020.04.03.023846.

36. Jeon, S., et al., Identification of antiviral drug candidates against SARS-CoV-2 from FDAapproved drugs. Antimicrob Agents Chemother, 2020.

37. Ko, M., et al., Comparative analysis of antiviral efficacy of FDA-approved drugs against SARSCoV-2 in human lung cells: Nafamostat is the most potent antiviral drug candidate. bioRxiv, 2020: p. 2020.05.12.090035.

38. Nixon, G.L., et al., Antimalarial pharmacology and therapeutics of atovaquone. The Journal of antimicrobial chemotherapy, 2013. 68(5): p. 977-985.

39. Li, P., et al., Characterization of plasma protein binding dissociation with online SPE-HPLC. Scientific Reports, 2015. 5(1): p. 14866.

40. Jin, Z., et al., Structure of M(pro) from COVID-19 virus and discovery of its inhibitors. Nature, 2020.

41. Cifuentes Kottkamp, A., et al., Atovaquone Inhibits Arbovirus Replication through the Depletion of Intracellular Nucleotides. Journal of virology, 2019. 93(11): p. e00389-19.

42. Yeo, A.E., et al., Effects of dual combinations of antifolates with atovaquone or dapsone on nucleotide levels in Plasmodium falciparum. Biochem Pharmacol, 1997. 53(7): p. 943-50.

43. Cushion, M.T., et al., Effects of atovaquone and diospyrin-based drugs on the cellular ATP of Pneumocystis carinii f. sp. carinii. Antimicrob Agents Chemother, 2000. 44(3): p. 713-9.

44. Jr, C.R.E., et al., Sialic acid-to-urea ratio as a measure of airway surface hydration. American Journal of Physiology-Lung Cellular and Molecular Physiology, 2017. 312(3): p. L398-L404.

45. Poitout-Belissent, F., S.N. Grant, and J.S. Tepper, Aspiration and Inspiration: Using Bronchoalveolar Lavage for Toxicity Assessment. Toxicol Pathol, 2021. 49(2): p. 386-396.

46. Calderon, M.M., et al., Efavirenz but Not Atazanavir/Ritonavir Significantly Reduces Atovaquone Concentrations in HIV-Infected Subjects. Clin Infect Dis, 2016. 62(8): p. 10361042.

47. Hughes, W., et al., Phase I safety and pharmacokinetics study of micronized atovaquone in human immunodeficiency virus-infected infants and children. Pediatric AIDS Clinical Trials Group. Antimicrobial agents and chemotherapy, 1998. 42(6): p. 1315-1318. 
48. Robin, C., et al., Plasma concentrations of atovaquone given to immunocompromised patients to prevent Pneumocystis jirovecii. Journal of Antimicrobial Chemotherapy, 2017. 72(9): p. 2602-2606.

49. Braithwaite, P.A., et al., Clinical pharmacokinetics of high dose mebendazole in patients treated for cystic hydatid disease. Eur J Clin Pharmacol, 1982. 22(2): p. 161-9.

50. Bekhti, A., Serum concentrations of mebendazole in patients with hydatid disease. Int J Clin Pharmacol Ther Toxicol, 1985. 23(12): p. 633-41.

51. Naccarelli, G.V., et al., Safety and efficacy of dronedarone in the treatment of atrial fibrillation/flutter. Clinical Medicine Insights. Cardiology, 2011. 5: p. 103-119.

52. SELDEN, R., T.W. SMITH, and W. Findley, Ouabain Pharmacokinetics in Dog and Man. Circulation, 1972. 45(6): p. 1176-1182.

53. Thapar, M.M., et al., Time-dependent pharmacokinetics and drug metabolism of atovaquone plus proguanil (Malarone) when taken as chemoprophylaxis. European Journal of Clinical Pharmacology, 2002. 58(1): p. 19-27.

54. Zsila, F. and I. Fitos, Combination of chiroptical, absorption and fluorescence spectroscopic methods reveals multiple, hydrophobicity-driven human serum albumin binding of the antimalarial atovaquone and related hydroxynaphthoquinone compounds. Org Biomol Chem, 2010. 8(21): p. 4905-14.

55. Hussein, Z., et al., Population pharmacokinetics of atovaquone in patients with acute malaria caused by Plasmodium falciparum. Clin Pharmacol Ther, 1997. 61(5): p. 518-30.

56. Mazzarino, R.C., Targeting Future Pandemics, a Case for De Novo Purine Synthesis and Basic Research. Front Immunol, 2021. 12: p. 694300.

57. Naim, M., et al., Solvated interaction energy (SIE) for scoring protein-ligand binding affinities. 1. Exploring the parameter space. J Chem Inf Model, 2007. 47(1): p. 122-33.

58. Ahmed, M.S., et al., Identification of tetracycline combinations as EphB1 tyrosine kinase inhibitors for treatment of neuropathic pain. Proceedings of the National Academy of Sciences, 2021. 118(10): p. e2016265118.

59. Neudert, G. and G. Klebe, DSX: a knowledge-based scoring function for the assessment of protein-ligand complexes. J Chem Inf Model, 2011. 51(10): p. 2731-45.

60. Schoggins, J.W., et al., Dengue reporter viruses reveal viral dynamics in interferon receptordeficient mice and sensitivity to interferon effectors in vitro. Proc Natl Acad Sci U S A, 2012. 109(36): p. 14610-5.

61. Shirato, K., M. Kawase, and S. Matsuyama, Middle East respiratory syndrome coronavirus infection mediated by the transmembrane serine protease TMPRSS2. J Virol, 2013. 87(23): p. 12552-61.

62. Studier, F.W., Protein production by auto-induction in high density shaking cultures. Protein Expr Purif, 2005. 41(1): p. 207-34.

63. Xue, X., et al., Production of authentic SARS-CoV M(pro) with enhanced activity: application as a novel tag-cleavage endopeptidase for protein overproduction. J Mol Biol, 2007. 366(3): p. 965-75.

64. Resnick, E., et al., Rapid Covalent-Probe Discovery by Electrophile-Fragment Screening. Journal of the American Chemical Society, 2019. 141(22): p. 8951-8968.

65. Mullen, A.R., et al., Oxidation of alpha-ketoglutarate is required for reductive carboxylation in cancer cells with mitochondrial defects. Cell Rep, 2014. 7(5): p. 1679-1690.

66. Kalvass, J.C. and T.S. Maurer, Influence of nonspecific brain and plasma binding on CNS exposure: implications for rational drug discovery. Biopharm Drug Dispos, 2002. 23(8): p. 32738. 